\title{
High-Performance Liquid Chromatographic Determination of Total Catecholamines and Metabolites in Human Urine by Application of the Fluorescence Derivatization Method for Their Free Form
}

\author{
Hitoshi Nohta, Hee-Kyoung Jeon, Masaaki KaI and Yosuke OHKura ${ }^{\dagger}$ \\ Faculty of Pharmaceutical Sciences, Kyushu University 62, Maidashi, Fukuoka 812, Japan
}

Keywords Total catecholamine, metabolite, urine, acid hydrolysis, free/total ratio, high-performance liquid chromatography, fluorescence

Catecholamines (CAs) and their metabolites are excreted in urine in free and conjugated forms (mainly sulfates, partially glucuronides). ${ }^{1} \quad$ Many assay methods for urinary free and total (free + conjugated) CA-related compounds have heretofore been reported for the biomedical investigations of CAs. ${ }^{2,3}$ Among the methods, high-performance liquid chromatography (HPLC) methods with electrochemical detection have been extensively used, but they do not have enough selectivity for the simultaneous determination of the CA-related compounds in urine; only several CA-related compounds can be quantified.

We have recently reported a reversed-phase HPLC method for the determination of CAs and their related compounds in the free form in human urine and plasma, based on postcolumn derivatization involving periodate oxidation followed by fluorescence reaction with meso1,2-diphenylethylenediamine. ${ }^{4}$ The purpose of this study was to apply the method to establish a method for the simultaneous determination of total CA-related compounds in human urine. After the hydrolysis of urine samples with perchloric acid, sample solutions for HPLC containing amino compounds [norepinephrine (NE), epinephrine (E), dopamine (DA), normetanephrine (NM), metanephrine (M), and 3-methoxytyramine (3MT)], and acidic and alcoholic compounds [3,4-dihydroxyphenylacetic acid (DOPAC), vanillylmandelic acid (VMA), homovanillic acid (HVA) and 4-hydroxy-3-methoxyphenylethyleneglycol (MOPEG)] were respectively prepared by solid-phase extraction on a strong cation-exchange cartridge, and subjected to HPLC. Isoproterenol (IP) was used as an internal standard. Concentration ratios of free to total forms in CA-related compounds were also discussed.

\footnotetext{
$\dagger$ To whom correspondence should be addressed.
}

\section{Experimental}

\section{Reagents, apparatus and material}

IP and standard samples of CAs and their metabolites were obtained as described previously. ${ }^{4} \quad \beta$-Glucuronidase/arylsulfatase (from helix pomatia) and arylsulfatase (arylsulfatase, from aerobactor aerogenes, type VI) were purchased from Calbiochem (La Jolla, USA) and Sigma (St. Louis, USA), respectively. Toyopak IC-SP S cartridge (sulfopropyl resin, $\mathbf{H}^{+}$form; TOSOH, Tokyo, Japan) was washed with $10 \mathrm{ml}$ of water and equilibrated with $2 \mathrm{ml}$ of $0.2 \mathrm{M}$ sodium phosphate buffer (pH 5.0) before use.

The HPLC system and its operation conditions were the same as described previously. ${ }^{4}$

Human urine $(24 \mathrm{~h})$ was collected in the presence of $10 \mathrm{ml}$ of $6 \mathrm{M}$ hydrochloric acid and stored at $-70^{\circ} \mathrm{C}$ until assay.

\section{Standard procedures with perchloric acid-hydrolysis}

For total amino compounds. To $0.3 \mathrm{ml}$ of urine were added $10 \mu \mathrm{l}$ of $30 \mathrm{nmol} \mathrm{ml}^{-1} \mathrm{IP}, 0.3 \mathrm{ml}$ of $1.0 \mathrm{M}$ perchloric acid, $30 \mu \mathrm{l}$ of $30 \mathrm{mM}$ EDTA $2 \mathrm{Na}$, and $40 \mu \mathrm{l}$ of $0.1 \mathrm{M}$ reduced glutathione, and the mixture was heated at $100^{\circ} \mathrm{C}$ for $20 \mathrm{~min}$ (hydrolysis). After cooling to room temperature, the mixture was combined with approximately $100 \mu \mathrm{l}$ of $2 \mathrm{M}$ potassium carbonate to adjust the $\mathrm{pH}$ to $6.0-6.5$. Then the mixture was centrifuged at $1000 \mathrm{~g}$ at $4^{\circ} \mathrm{C}$ for $5 \mathrm{~min}$. The resulting supernatant $(0.6 \mathrm{ml})$ was poured onto a Toyopak IC-SP $\mathrm{S}$ cartridge. The cartridge was washed successively with $5 \mathrm{ml}$ of water (twice), then with $0.5 \mathrm{ml}$ of aqueous $50 \%$ (v/ v) ethanol and finally with another $5 \mathrm{ml}$ of water. The amino compounds, including IP, in the cartridge were eluted with $0.5 \mathrm{ml}$ of a mixture of $1.5 \mathrm{M}$ potassium chloride prepared in $100 \mathrm{mM}$ hydrochloric acid and methanol $(93 / 7, v / v)$. The eluate was used as an HPLC sample for the amino compounds (amine fraction).

For total acidic and alcoholic compounds. The 
sample of urine $(0.3 \mathrm{ml})$ was treated in the same manner as for the amino compounds for hydrolysis, except that an addition of IP was omitted and heating time was prolonged to $30 \mathrm{~min}$. The resulting mixture was combined with approximately $70 \mu \mathrm{l}$ of $2.0 \mathrm{M}$ potassium carbonate to adjust to $\mathrm{pH} 1.5-1.7$. Then this mixture was centrifuged at $1000 \mathrm{~g}$ at $4^{\circ} \mathrm{C}$ for $5 \mathrm{~min}$. The resulting supernatant $(0.5 \mathrm{ml})$ was poured onto a Toyopak IC-SP $\mathrm{S}$ cartridge: this cartridge was washed with $1.5 \mathrm{ml}$ of water. The effluent and washings were combined, and to the mixture was added $10 \mu \mathrm{l}$ of $30 \mathrm{nmol} \mathrm{ml}^{-1}$ IP (acidalcohol fraction).

The amine and acid-alcohol fractions were passed through a membrane filter (Maishori Disc W-3-5, TOSOH), respectively, and then $100 \mu$ l-portions were subjected to HPLC.

\section{Results and Discussion}

Figure 1 shows typical chromatograms of the amine and acid-alcohol fractions obtained with perchloric acidhydrolyzed urine from a healthy person. The peaks were identified by the previously described technique. ${ }^{4}$

In hydrolyzed urine samples, the concentrations of amino compounds are generally lower than those of the acidic and alcoholic compounds. There also exist unknown compounds convertible to fluorescent compounds in the postcolumn derivatization which interfere with the detection of the target compounds in HPLC. The amino compounds and the acidic and alcoholic compounds in hydrolyzed urine sample should be fractionated prior to subjecting the sample to HPLC. The solid-phase extraction procedure using a cationexchange cartridge (Toyopak IC-SP S) served not only to prepare amine and acid-alcohol fractions (extract, amine fraction; effluent from the cartridge, acid-alcohol fraction) but also to remove the unknown compounds. The $\mathrm{pH}$ value of the applied sample affected the recoveries of the CA-related compounds and the removal of the unknown compounds; the most favorable results were attained at $\mathrm{pH} 6.0-6.5$ for the amino compounds and at pH 1.5-1.7 for the acidic and alcoholic compounds. The recoveries of the standard compounds added to $0.3 \mathrm{ml}$ of urine in amounts of $5 \mathrm{nmol}$ for VMA and MOPEG and $50 \mathrm{pmol}$ for the others and IP were $74 \%$ for HVA, 95\% for MOPEG, and $80-95 \%$ for the others and IP with the relative standard deviations ( $R S D, n=5$ ) less than $2.0 \%$.

In the hydrolysis at $100^{\circ} \mathrm{C}$ of urine sample, the maximum amounts of the amino compounds and the acidic and alcoholic compounds were liberated upon
(A)

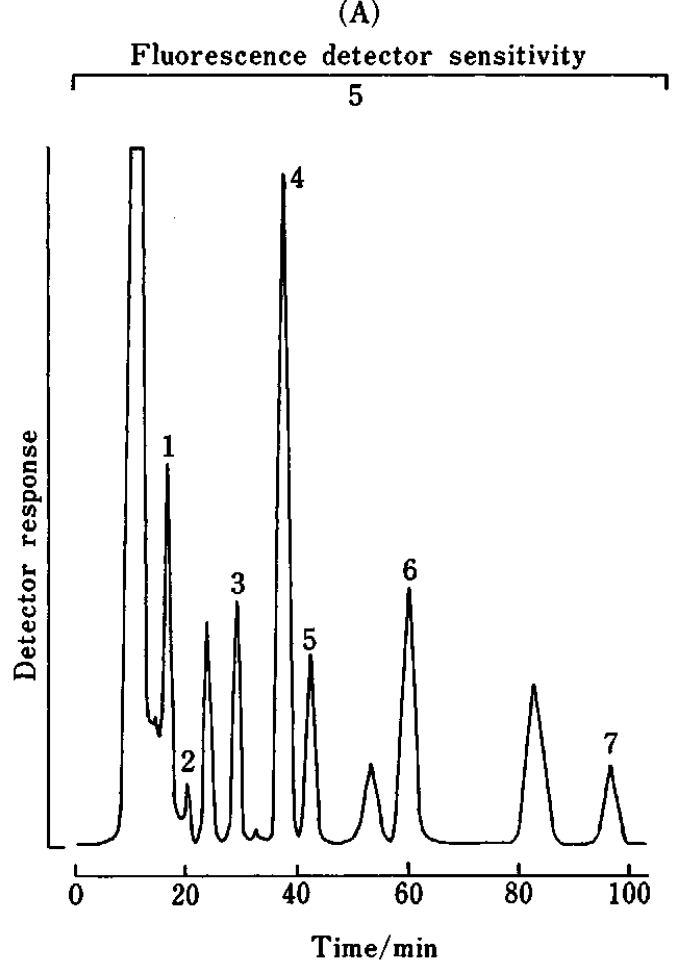

(B)

$\overbrace{5}^{\text {Fluorescence detector sensitivity }}$

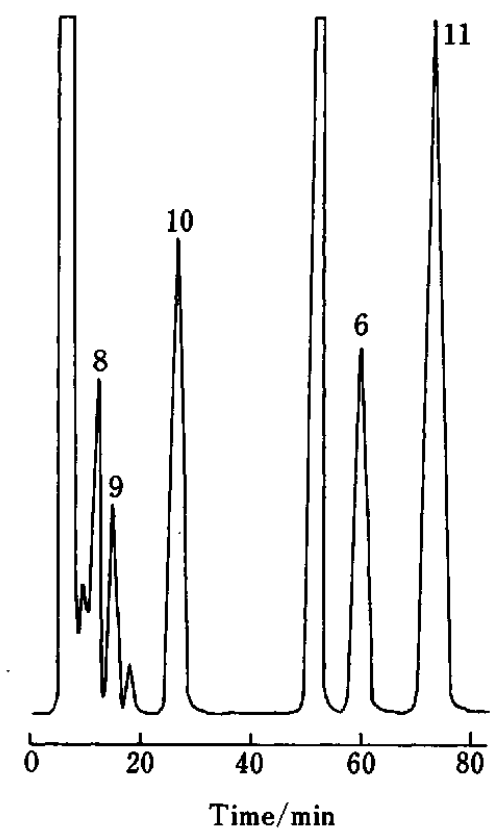

Fig. 1 Chromatograms of (A) amine and (B) acid-alcohol fractions obtained by treating a human urine sample according to the procedure. Peaks and concentrations (nmol mol ${ }^{-1}$ urine) in parentheses: 1 , NE (1.26); 2, E (0.18); 3, NM (1.41); 4, DA (6.15); 5, M (0.93); 6, IP (internal standard); 7, 3MT (1.05); 8, VMA (22.7); 9, MOPEG (243); 10, DOPAC (6.64); 11, HVA (36.9); others, unidentified, probably catechol or 4-hydroxy-3-methoxyphenyl compounds. 
Table 1 Amounts of free (F) and total (T) catecholamines and their amino, and acidic and alcoholic metabolites in urine from healthy persons $\left(\mu \mathrm{mol} / 24 \mathrm{~h}^{-1}\right)$

\begin{tabular}{|c|c|c|c|c|c|c|c|c|c|c|}
\hline \multirow{3}{*}{ Sex } & \multirow{3}{*}{ Age } & \multicolumn{9}{|c|}{ Catecholamine } \\
\hline & & \multicolumn{3}{|c|}{ NE } & \multicolumn{3}{|c|}{$\mathrm{E}$} & \multicolumn{3}{|c|}{ DA } \\
\hline & & $\mathbf{F}$ & $\mathrm{T}$ & $\mathrm{F} / \mathrm{T}$ & $\mathrm{F}$ & $\mathrm{T}$ & $\mathrm{F} / \mathrm{T}$ & $\mathbf{F}$ & $\mathrm{T}$ & $\mathbf{F} / \mathbf{T}$ \\
\hline $\mathbf{M}$ & 44 & 0.40 & 1.25 & 0.32 & 0.10 & 0.37 & 0.26 & 1.52 & 5.67 & 0.27 \\
\hline $\mathbf{M}$ & 39 & 0.35 & 1.56 & 0.23 & 0.09 & 0.19 & 0.44 & 1.45 & 4.33 & 0.34 \\
\hline $\mathbf{M}$ & 33 & 0.59 & 2.09 & 0.28 & 0.10 & 0.59 & 0.18 & 1.99 & 5.06 & 0.39 \\
\hline $\mathbf{M}$ & 28 & 0.29 & 1.54 & 0.19 & 0.07 & 0.23 & 0.29 & 0.82 & 8.82 & 0.21 \\
\hline $\mathbf{M}$ & 27 & 0.28 & 1.04 & 0.27 & 0.08 & 0.32 & 0.24 & 1.84 & 7.31 & 0.25 \\
\hline $\mathbf{M}$ & 25 & 0.35 & 1.75 & 0.20 & 0.07 & 0.48 & 0.14 & 2.03 & 9.44 & 0.22 \\
\hline $\mathbf{F}$ & 30 & 0.17 & 1.59 & 0.11 & 0.05 & 0.18 & 0.31 & 1.43 & 5.41 & 0.08 \\
\hline $\mathbf{F}$ & 25 & 0.38 & 2.39 & 0.16 & 0.09 & 0.27 & 0.35 & 1.82 & 6.40 & 0.29 \\
\hline $\mathbf{F}$ & 24 & 0.24 & 0.99 & 0.25 & 0.07 & 0.22 & 0.31 & 0.72 & 6.73 & 0.11 \\
\hline $\mathbf{F}$ & 22 & 0.28 & 1.30 & 0.21 & 0.05 & 0.08 & 0.61 & 1.09 & 6.15 & 0.18 \\
\hline Mean & & 0.33 & 1.55 & 0.22 & 0.08 & 0.29 & 0.31 & 1.57 & 6.53 & 0.23 \\
\hline \multirow[t]{2}{*}{ SD } & & 0.11 & 0.42 & 0.06 & 0.02 & 0.15 & 0.13 & 0.32 & 1.53 & 0.09 \\
\hline & & \multicolumn{9}{|c|}{ Amino metabolite } \\
\hline \multirow[t]{2}{*}{$\operatorname{Sex}$} & Age & \multicolumn{3}{|c|}{ NM } & \multicolumn{3}{|c|}{$\mathbf{M}$} & \multicolumn{3}{|c|}{$3 \mathrm{MT}$} \\
\hline & & $\mathbf{F}$ & $\mathrm{T}$ & $\mathrm{F} / \mathrm{T}$ & $\mathrm{F}$ & $\mathrm{T}$ & $\mathrm{F} / \mathrm{T}$ & $\mathbf{F}$ & $\mathrm{T}$ & $\mathrm{F} / \mathrm{T}$ \\
\hline $\mathbf{M}$ & 44 & 0.83 & 3.84 & 0.22 & 0.22 & 0.93 & 0.24 & 0.25 & 1.37 & 0.19 \\
\hline $\mathbf{M}$ & 39 & 0.64 & 1.87 & 0.34 & 0.13 & 0.75 & 0.17 & 0.36 & 1.76 & 0.20 \\
\hline $\mathbf{M}$ & 33 & 0.19 & 1.41 & 0.13 & 0.15 & 0.73 & 0.20 & 0.16 & 0.79 & 0.20 \\
\hline $\mathbf{M}$ & 28 & 0.43 & 2.30 & 0.19 & 0.14 & 0.54 & 0.26 & 0.14 & 0.60 & 0.23 \\
\hline $\mathbf{M}$ & 27 & 0.47 & 2.70 & 0.17 & 0.17 & 0.93 & 0.18 & 0.23 & 1.05 & 0.22 \\
\hline $\mathbf{M}$ & 25 & 0.13 & 0.53 & 0.25 & 0.12 & 0.40 & 0.30 & 0.50 & 1.51 & 0.33 \\
\hline$F$ & 30 & 0.16 & 0.69 & 0.23 & 0.11 & 0.84 & 0.14 & 0.18 & 1.68 & 0.11 \\
\hline $\mathrm{F}$ & 25 & 0.35 & 1.00 & 0.35 & 0.18 & 0.63 & 0.29 & 0.18 & 0.67 & 0.27 \\
\hline $\mathbf{F}$ & 24 & 0.27 & 1.50 & 0.18 & 0.09 & 0.99 & 0.09 & 0.22 & 1.23 & 0.18 \\
\hline $\mathbf{F}$ & 22 & 0.23 & 1.54 & 0.15 & 0.08 & 0.65 & 0.13 & 0.26 & 1.34 & 0.19 \\
\hline Mean & & 0.37 & 1.74 & 0.22 & 0.14 & 0.74 & 0.20 & 0.25 & 1.12 & 0.21 \\
\hline \multirow[t]{2}{*}{ SD } & & 0.22 & 0.55 & 0.07 & 0.04 & 0.18 & 0.07 & 0.10 & 0.39 & 0.06 \\
\hline & & \multicolumn{9}{|c|}{ Acidic metabolite } \\
\hline Sex & Age & & DOPAC & & & HVA & & & $\mathrm{VM}$ & \\
\hline & & $\mathrm{F}$ & $\mathrm{T}$ & $\mathrm{F} / \mathrm{T}$ & $F$ & $\mathrm{~T}$ & $\mathrm{~F} / \mathrm{T}$ & $F$ & $\mathrm{~T}$ & $\mathrm{~F} / \mathrm{T}$ \\
\hline $\mathbf{M}$ & 44 & 3.76 & 5.89 & 0.65 & 30.4 & 33.8 & 0.90 & 25.2 & 25.2 & 1.00 \\
\hline $\mathbf{M}$ & 39 & 4.87 & 6.02 & 0.81 & 24.3 & 27.9 & 0.87 & 19.4 & 19.7 & 0.98 \\
\hline $\mathbf{M}$ & 33 & 4.21 & 7.91 & 0.53 & 32.5 & 34.9 & 0.93 & 23.7 & 24.3 & 0.98 \\
\hline $\mathbf{M}$ & 28 & 6.95 & 10.35 & 0.67 & 34.2 & 40.0 & 0.85 & 22.7 & 22.7 & 1.00 \\
\hline $\mathrm{M}$ & 27 & 8.04 & 10.15 & 0.79 & 25.7 & 29.3 & 0.88 & 18.7 & 18.9 & 0.99 \\
\hline $\mathbf{M}$ & 25 & 7.05 & 10.21 & 0.69 & 32.8 & 36.9 & 0.89 & 28.4 & 28.7 & 0.99 \\
\hline $\mathrm{F}$ & 30 & 8.24 & 15.32 & 0.54 & 28.5 & 36.4 & 0.78 & 22.6 & 22.6 & 1.00 \\
\hline $\mathrm{F}$ & 25 & 3.82 & 5.27 & 0.73 & 22.7 & 24.5 & 0.91 & 21.3 & 21.5 & 0.99 \\
\hline $\mathrm{F}$ & 24 & 3.37 & 5.67 & 0.59 & 16.8 & 24.1 & 0.70 & 27.7 & 28.0 & 0.99 \\
\hline $\mathrm{F}$ & 22 & 5.12 & 8.46 & 0.61 & 20.4 & 22.6 & 0.90 & 17.6 & 17.7 & 0.99 \\
\hline Mean & & 5.54 & 8.52 & 0.66 & 26.8 & 31.0 & 0.86 & 22.7 & 22.9 & 0.99 \\
\hline SD & & 1.76 & 2.96 & 0.09 & 5.5 & 5.8 & 0.07 & 3.5 & 3.5 & 0.01 \\
\hline & & $\mathrm{Alc}$ & blic met & lite & & & & & & \\
\hline Sex & Age & & MOPEC & & & & & & & \\
\hline & & $\mathrm{F}$ & $T$ & $F / T$ & & & & & & \\
\hline $\mathbf{M}$ & 44 & 1.92 & 21.2 & 0.09 & & & & & & \\
\hline $\mathbf{M}$ & 39 & 1.68 & 16.3 & 0.10 & & & & & & \\
\hline $\mathbf{M}$ & 33 & 1.72 & 19.8 & 0.09 & & & & & & \\
\hline $\mathbf{M}$ & 28 & 1.83 & 22.0 & 0.08 & & & & & & \\
\hline $\mathbf{M}$ & 27 & 1.94 & 18.7 & 0.10 & & & & & & \\
\hline M & 25 & 2.04 & 24.3 & 0.08 & & & & & & \\
\hline $\mathrm{F}$ & 30 & 1.37 & 21.5 & 0.06 & & & & & & \\
\hline $\mathbf{F}$ & 25 & 1.13 & 16.5 & 0.07 & & & & & & \\
\hline$F$ & 24 & 1.71 & 23.5 & 0.07 & & & & & & \\
\hline $\mathbf{F}$ & 22 & 1.64 & 12.9 & 0.13 & & & & & & \\
\hline Mean & & 1.70 & 19.7 & 0.09 & & & & & & \\
\hline SD & & 0.26 & 3.4 & 0.02 & & & & & & \\
\hline
\end{tabular}

a. Measured by the previously reported method. ${ }^{4}$ 
heating for $20-30 \mathrm{~min}$ and $30-60 \mathrm{~min}$, respectively; heating for 20 and for $30 \mathrm{~min}$ were selected. Almost maximum amounts of the $\mathrm{CA}$-related compounds were liberated at perchloric acid concentrations of $0.8-1.0 \mathrm{M}$; $1.0 \mathrm{M}$ was selected. EDTA $2 \mathrm{Na}$ and reduced glutathione well prevented the degradation of CA-related compounds; in their absence, $6.5-25 \%$ of CA-related compounds were decomposed during the hydrolysis procedure.

$\beta$-Glucuronidase/arylsulfatase $(0.35-1.8$ and $0.10-$ 0.5 units per tube, respectively) and arylsulfatase ( $0.05-$ 0.3 units per tube)-mediated hydrolyses were provided the same values of the CA-related compounds as those given by the perchloric acid-hydrolysis except for VMA; the peak for VMA was overlapped with unknown earlyeluting peaks.

Linear relationships were obtained between the ratios of the peak heights of CA-related compounds to that of IP and the amounts of the compounds added to $0.3 \mathrm{ml}$ of urine in the range $10-3000 \mathrm{pmol}$ for VMA and MOPEG, and $0.2-200 \mathrm{pmol}$ for others. The detection limits (pmol ml ${ }^{-1}$ urine, $S / N=5$ ) were $0.3(\mathrm{NE}), 0.7(\mathrm{E}), 2$ (DA), 0.4 (NM), 1 (M), 2(3MT), 5(DOPAC), 60 (VMA), 5 (HVA) and 90 (MOPEG). The precision of the method was established by repeated determinations $(n=5)$ of the urine sample used for Fig. 1; the RSD values (\%) for VMA and MOPEG were 4.5 and 5.0, respectively, and those for the other CA-related compounds were less than 3.0.

The concentrations of CA-related compounds in $24 \mathrm{~h}$ urine from 10 healthy persons were measured by the present methods (Table 1). The concentration ratios of free to total forms in individual CA-related compounds in human urine were $0.20-0.31$ for the amino compouds, 0.09 for the alcoholic compound and $0.66-0.99$ for the acidic compounds. The peaks for 3,4-dihydroxymandelic acid and 3,4-dihydroxyphenylethyleneglycol in urine sample were overlapped with early-eluting peaks (retention times, around $10 \mathrm{~min}$ ); these compounds were indeterminable. When this method was applied to human plasma, recoveries of the amino compounds from the cartridge were not reproducible. The present method is sensitive and selective, and permits ten total CA-related compounds to be quantified by two HPLC runs (namely, for the amine, and the acid-alcohol fractions). Therefore, this method should be useful for biomedical and clinical investigations.

\section{References}

1. L. P. O'Gorman, O. Borud, L. A. Khan and L. R. Gjessing, Clin. Acta, 29, 111 (1970).

2. S. W. Dziedzic, L. M. Dziedzic and S. E. Gitlow, in "Quantitative Analysis of Catecholamines and Related Compounds", ed. A. M. Krstulović, p. 13, Ellis Horwood, Chichester, 1986.

3. B. Kågedal and D. S. Goldstein, J. Chromatogr., 429, 177 (1988).

4. H.-K. Jeon, H. Nohta and Y. Ohkura, Anal. Biochem., 200, 332 (1992).

(Received May 6, 1993)

(Accepted June 21, 1993) 